\title{
Integrated Approach for Heat Transfer in Fluidized Bed Reactors
}

\author{
Zeeshan Nawaz ${ }^{1}$, Shahid Naveed ${ }^{2}$, Naveed Ramzan² and Fei Wei \\ ${ }^{1}$ Beijing Key Laboratory of Green Chemical Resection Engineering and Technology \\ (FLOTU) Department of Chemical Engineering, Tsinghua University, \\ ${ }^{2}$ Department of Chemical Engineering, University of Engineering and Technology, Lahore, \\ ${ }^{1}$ P. R. China \\ ${ }^{2}$ Pakistan
}

\section{Introduction}

Fluidization of gas-solid system is long-standing subject of basic research. As a result of fluid-particle intensive contact, an isothermal system with superior heat and mass transfer abilities favors its use for chemical reactions, mixing, drying, and other applications. Inspire of huge benefits, number of problems are still associated with gas-solid fluidization system. Solid properties, in particular, particle size and size distribution significantly affect the interaction/contacting between particles, their movement and the fluid-particle mixing. Distinct macroscopic phenomena of plug formation, channeling and particle agglomeration was observed with increasing superficial gas velocity in conventional fluidized bed of fine/nano-particles (group $\mathrm{C}$ in the Geldart classification) due to strong interparticle forces.

The concept of powder-particle fluidized bed (PPFB) was first introduced by Kato et al. in early 1990s [1]. It is known to be a useful technique to fluidize group C particles without external aid like acoustic, centrifugal, magnetic, stirring and/or vibrating fields, etc. In the PPFB process, fine powders (group C) are fluidized with coarse particles (group B). The bimodal fluidized bed system at steady state gives a certain stable hold-up of fine powders in the bed [2]. Many investigators, Sun and Grace [3], and Xue et al. [4] studied bi-modal fluidization in bubbling or turbulent regimes, while, Wei et al. [5] and Du [6, 7] concentrate on CFBs. The investigation of Xue et al. showed that by adding coarse particles fluidization quality of fine particles could improve [4]. Extensive studies of Wei et al. indicated that the addition of coarse particles to a fluid catalytic cracking (FCC) riser decreased the lateral solids mixing and had insignificant influence on axial solids mixing [5]. Du et al. studied the axial and lateral mixing by using tracer particles of different sizes in a FCC riser and found that the axial solids back mixing increased, while radial solids mixing decreased with the increase of particle size and density. Recently, Zeeshan et al. explained bi-modal/bi-particle fluidized bed system hydrodynamics, attrition, mixing behaviour, and its applications [8].

Stable and uniform heat transfer in Fluidized Bed Reactors (FBR) without providing provisions of external or internal source is a difficult task for designers. As continuous heat supply and deduction is a necessary part of FBR operation for controlling highly endothermic and exothermic reactions, respectively. The state-of-the-art idea of bi-modal particle (Gas-Solid-Solid) fluidization is given by FLOTU, in order to overcome above said reaction barriers in a fluidized bed technology. In this chapter, a comprehensive overview of 
GSS-FRB research was discussed with practical example of direct propane dehydrogenation reaction. Direct propane dehydrogenation is complicated in engineering constraints due to equilibrium limitations and endothermic nature of reaction, therefore, continuous supply of heat is required. The superiority of GSS-FBR operation was discussed and compared from hydrodynamics to reaction results. The results of fixed bed micro-reactor and integrated bimodal particle fluidized bed reactors were compared, and parametrically characterized. The significant features of this technique was also highlighted and proposed intensified design as a promising opportunity for highly endothermic and exothermic reactions through FBR, with both economic and operational benefits.

\section{Integrated approach}

In order to get fluidized bed technology in operation for high endothermic or exothermic reactions Zeeshan et al. proposed a unique design of co-fluidized bed reactor, where coarse particles sized catalyst was co-fluidized with fine FCC catalyst $[9,10]$. Coarse particles serve as principal catalyst for desired reaction (endothermic/exothermic), while fine particles serve as a heat carrier/heat absorbent. For an endothermic reaction: the fine catalyst particles take heat from regenerator, transfer heat to principal catalyst (coarse particles) in a fluidized bed reactor and then may serve as secondary catalyst in other reactors like olefins inter-conversion, MTO, MTP, etc as shown in Figure 1.

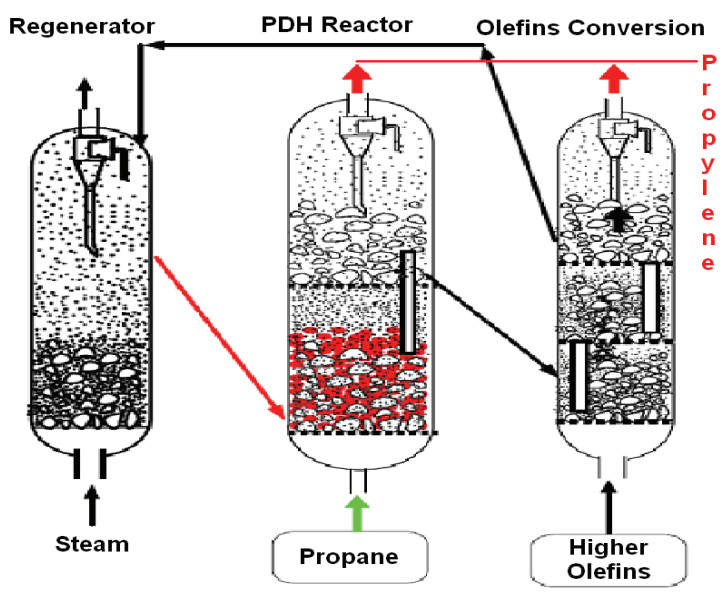

Fig. 1. Proposed process design and reactors sequence

\section{Features of technology}

Gas-solid-solid (GSS) fluidization system is a unique piece of equipment and its features related to the better mixing quality. The mixing and hydrodynamic behavior of FCC particles with coarse particles was investigated in 2D and 3D co-fluidized beds respectively. The reason of enhancing mixing and fluidization properties by adding coarse particles is particularly due to the movement of coarse particles, those breaks the strong interparticle forces between FCC particles and destroy bubble wake (bubble disassociation strategy), time to time. The information about the design of $2 \mathrm{D}$ and $3 \mathrm{D}$ co-fluidized bed reactors, and experimental specification can be find elsewhere [8]. 
To process the solid particulates in fluidized bed and slurry phase reactors, attrition is an inevitable consequence and is therefore one of the preliminary parameters for the catalyst design for a fluidized bed reactor. The mechanical degradation propensity of the zeolite catalysts (particles) were investigated in a bi-modal distribution environment using a Gas Jet Attrition - ASTM standard fluidized bed test (D-5757) [11]. The experimentation was conducted in order to explore parameters affecting attrition phenomena in a bimodal fluidization. In a bimodal fluidization system, two different types of particles were cofluidized isothermally. Detailed information about experimentation design can be found elsewhere [12].

\subsection{Mixing behaviour}

The formation, breakage and growth of bubbles are definitive for fluidization, heat exchange and mixing efficiency. Fluidization occurs particularly as a result of a dynamic balance between gravitational forces and forces of a fluid through bed. For the systems where the fluidizing particles have significantly different densities and sizes, those create instable local pockets of very high void fraction termed bubbles. This system is known as self-excited nonlinear system. Previously, it is known that periodic perturbation of a system parameter may result in chaos suppression. Here we examine uniform mixing in co-fluidization (GSS), and noted a unique bubble braking phenomena that is principally responsible for uniform mixing. After the formation of bubble, the bubble flow pattern and pressure distribution are sensitive to the block arrangement.
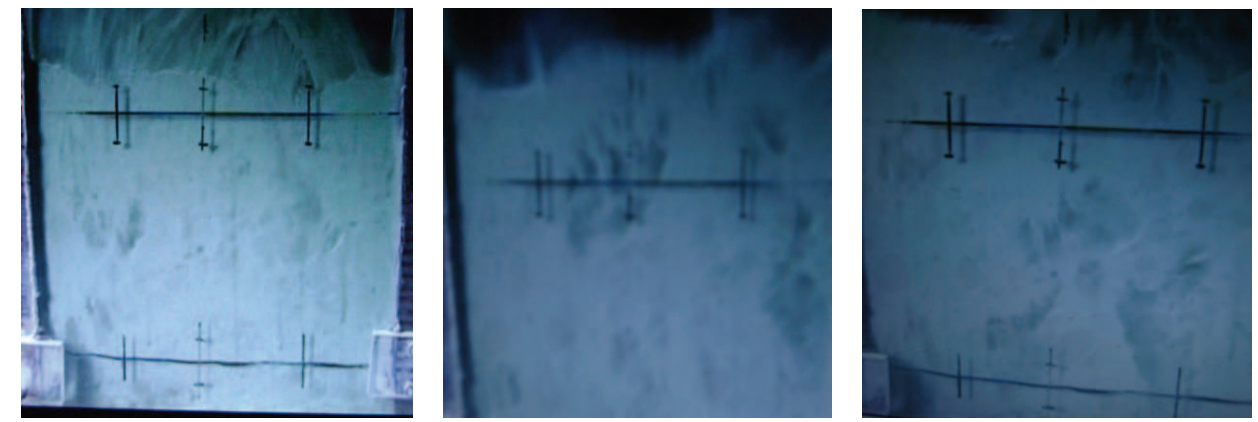

Fig. 2. Unique bubble braking phenomena of GSS fluidization

In bi-modal particle system (GSS FBR) the large bubbles were broken down into small bubbles. This occurs when coarse particles will break large bubble wake's, and generated bubbles give swirl. Momentum was transferred by the bubble to solids in both axial and lateral directions that enhance mixing. The coarse particles produce a high frequency of bubbles and low pressure amplitude around the orifice in comparison with additional distributer, and in ultimate promote smoother fluidization of FCC catalyst with high/uniform mixing. However, coarse particles throughout the bed are in idealistic symmetrical flow, and no jammed was observed. This phenomenon was captured from 2D co-fluidized bed and shown in Figure. 2 [8].

\subsection{Hydrodynamics of co-fluidization}

After fundamental description of the role of the bubbles in a bi-modal fluidized bed, hydrodynamic of FCC particles with coarse particles was investigated. On the whole, 


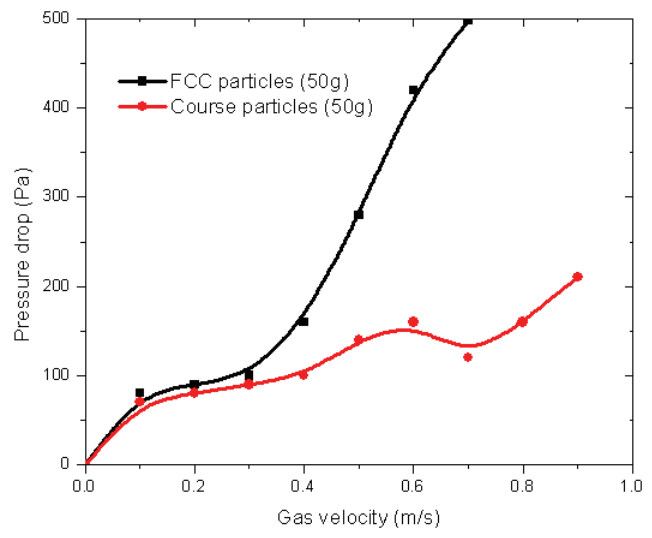

(a)

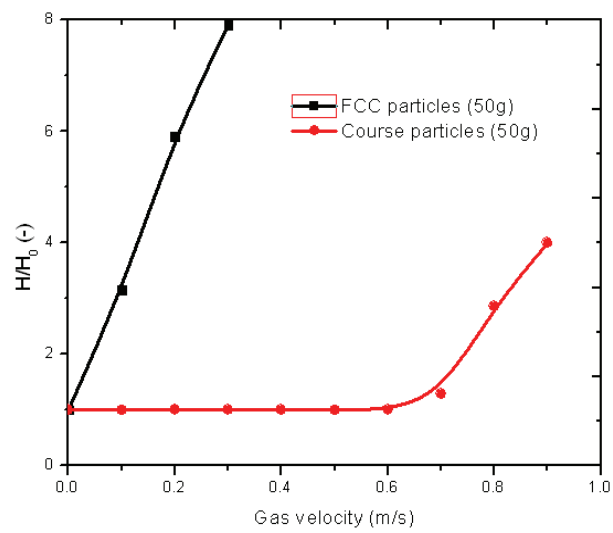

(b)

Fig. 3. (a) Bed pressure drop curve of FCC and coarse particles, (b) Bed expansion curve of FCC and coarse particles

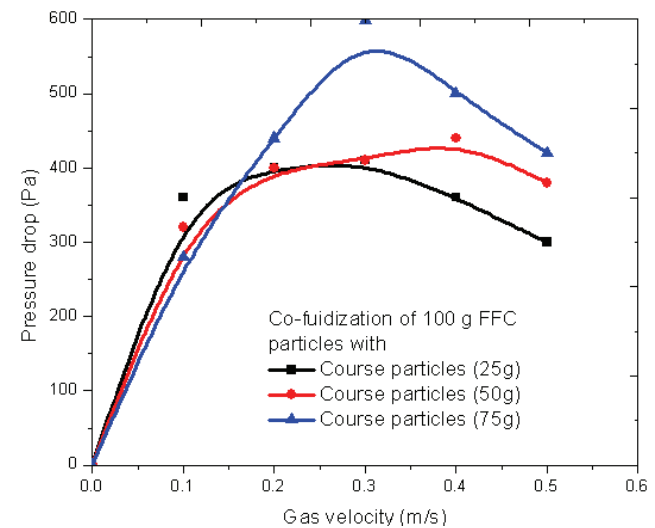

(a)

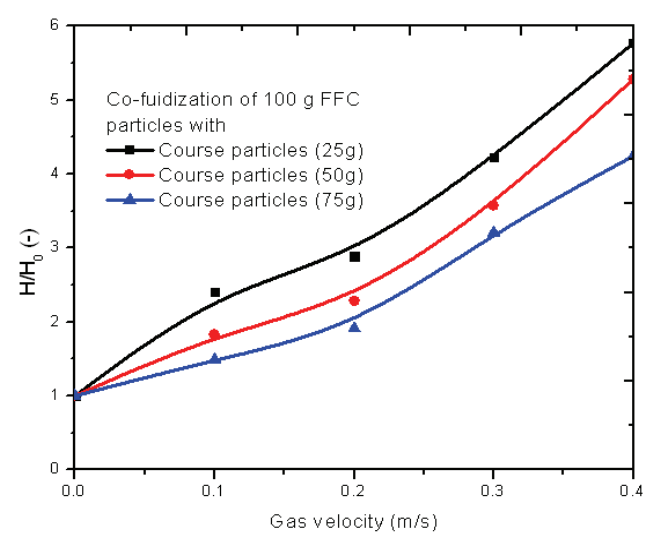

(b)

Fig. 4. (a) Bed pressure drop during co-fluidization of FCC and coarse particles, (b) Bed expansion during co-fluidization of FCC and coarse particles

fluidization properties and mixing was improved. Therefore, here we focus our attention on the overall behavior of the bed. The fluidization of FCC catalyst shows crack formation at low superficial gas velocities. With the increase of the gas velocity to around $0.1 \mathrm{~m} / \mathrm{s}$, the FCC particles become fluidizing and their fine counter parts air borne at the upper part of the bed. The experimental results of the pressure drop and bed height ratio, of FCC and coarse particles bed (independently) are shown in Figure 3 (a) and (b), respectively. This is the reason that the bed height ratio of FCC particle is become violent with small increase in velocity. The upper part of bed demonstrates very dilute bed, but in turbulent fluidization behavior. The bed surface was severely disturbed by large gas bubble eruptions and fine particle ejections, which lead to enormous elutriation. While, coarse particles also feel difficulty in fluidization at lower gas velocities, till $0.3 \mathrm{~m} / \mathrm{s}$. With the increase of gas velocity, the pressure drop curves do not show a plateau. Figure 3 (b) shows that the 
expansion of FCC particles bed is much higher than that of the coarse particles bed. This gap can be modified by decreasing the particle size difference. The physical mixture of FCC particles with coarse particles was made in following ratio: The FCC particles were fixed to $100 \mathrm{~g}$, with coarse particles were added as 25,50 and $75 \mathrm{~g}$. Details about the gross bed behavior, pressure drop and expansion characteristics are shown in Figure 4 (a) and (b). The addition of coarse particles in different quantity to FCC particles has improved the gross fluidization behavior significantly. Furthermore, the minimum fluidization velocity of the mixture decreases. In co-fluidization system, it's difficult to measure $\Delta \mathrm{P}$ across single type of particles (either for small or coarse) as they are well mixed.

\subsection{Attrition study}

Several experimental studies and empirical models were developed in order to characterize the extent of attrition in a fluidized environment. Gwyn et. al. [12] developed the following empirical relationship (see equation 1) by considering shearing time of attrition, using single particle system with high velocity air jets in a fluidized bed. The Gwyn constants $\mathrm{K}$ and $\mathrm{m}$, were the function of material properties and size, and determined experimentally; further details can be find elsewhere [12].

$$
W=K t^{m}
$$

However, to date, no study has focused on particles attrition phenomena (systematically explained in Figure 5) in bi-modal particles fluidized bed (co-fluidization environments) and multi-particle sized system, i.e. the most feasible design for handling extremely endothermic or exothermic reactions, while, disadvantage of attrition become serious. Therefore the study focused attention not only on attrition calculations, but explore its incremental phenomena and develop a more generalizes relationship for calculating attrition debris in bi-model particle system.
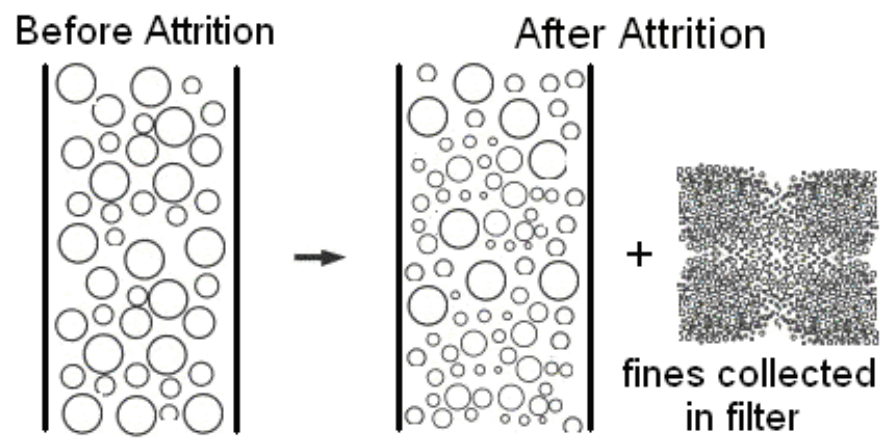

Fig. 5. Systematic image of attrition tube before and after attrition run

AJI in certain cases was as high as 0.28 , means that $28 \%$ of the small particles were lost due to attrition. The attrition evaluation was generally pronounced by the attrition rate which depends upon certain thresh hold for the size limit of fines collected. In practice, attrition mass was more important than the collected fine's size distribution, therefore ASTM standard D-5757 attrition test method was selected for the present study and operated under standard operating procedure, in the density range of $1-3 \mathrm{~g} / \mathrm{cm}^{3}$ [12]. The flow regime changes with density variations and fluidization velocities, but settling chamber provides 

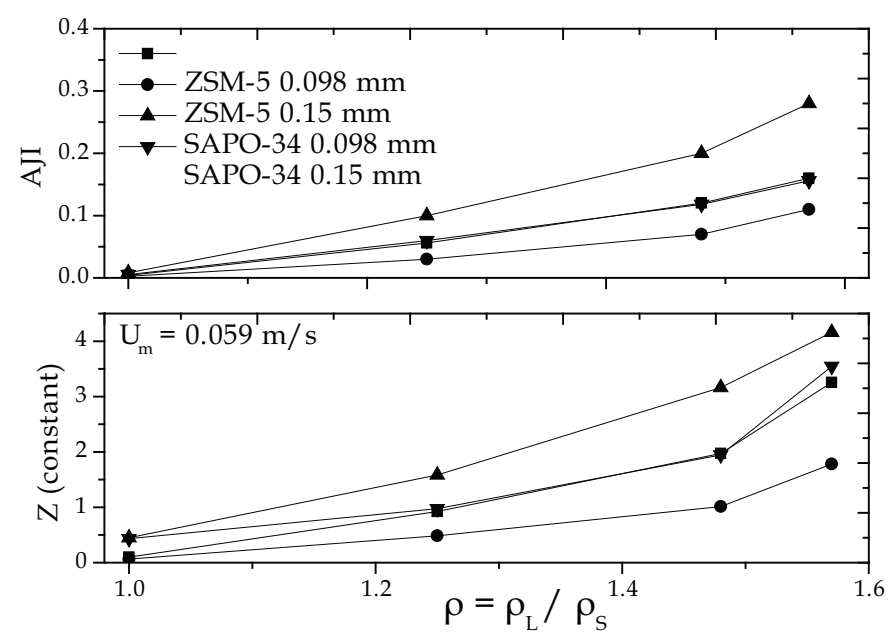

Fig. 6. Effect of relative density on newly defined constant $Z$ and AJI after $5 \mathrm{hr}$

slipping area to keep the particles airborne in these circumstances, and only let the fines go out. Therefore ASTM standard fluidized bed was selected and operated at fixed superficial gas velocity i.e. $0.059 \mathrm{~m} / \mathrm{s}$ according to the standard operating procedure. The exact values of Gwyn constants for each particle (small zeolite catalysts) at standard conditions were evaluated in accord with an exact protocol.

Effect of relative density was considered to define this new constant $Z$ and its influence can be observed in Figure 6 . There it was assumed that $S$ was constant and its value is 1 . This newly developed function (equation 2) has the ability to successfully explain small particles attrition of zeolites and other synthetic catalysts used in bimodal fluidized bed reactors. This empirical relationship will become more generalized and accurate because Gwyn constants of each particle (catalyst) were determined individually. Therefore the applicability of this function was not only limited to the measurement of zeolites attrition in a bimodal fluidized bed environment but can be used for other catalysts. The narrow span of deviation i.e. \pm 0.50 $\mathrm{g}$ in attrition debris after 5.0 hours operation was observed. The model was generalized as changes related to material properties, and by considering these properties the relationship was made generalized. For each type of material first determine the values of their constants for single particle system as explained by Gwyn, and then using proposed model the attrition loss of that sample in a bi-model fluidization at designated conditions can be calculated.

$$
x=(\rho)^{5} \cdot(S)^{0.44} \cdot(K) \cdot(t)^{1.53 m}
$$

The attrition phenomena of small particles in a bimodal particles fluidized bed was found different from single particle fluidized bed phenomena's, because in this system fracture mechanism plays vital role in increasing attrition. Moreover, the power of impact was observed to be the function of large particle density and size ratios.

\section{Case study}

The proposed bi-modal fluidized bed has wide application in chemical industry in particular for the exothermic and endothermic reactions. At present a complete case study of 
direct propane dehydrogenation is discussed using bi-modal fluidized bed technology [10]. The propane dehydrogenation is the most economical route to propylene, but very complex due to endothermic reaction requirements, equilibrium limitations, stereo-chemistry and in engineering constraints. The state of the art idea of bi-model particle (Gas-Solid-Solid) fluidization was applied, in order to overcome alkane dehydrogenation reaction barriers in a fluidized bed technology. In this study, the propane dehydrogenation reaction was studied in an integrated fluidized bed reactor, using Pt-Sn/ $\mathrm{Al}_{2} \mathrm{O}_{3}-\mathrm{SAPO}-34$ novel catalyst (ZeeFLOTU) at $590{ }^{\circ} \mathrm{C}$. The results of fixed bed micro-reactor and integrated bi-model particle fluidized bed reactors were compared, and parametrically characterized. The results showed that the propylene selectivity is over $95 \%$, with conversion between $31-24 \%$. This significant enhancement is by using novel bi-model particle fluidization system, owing to uniform heat transfer throughout the reactor and transfer coke from principal catalyst to secondary catalyst, which increases principal catalyst's stability. Experimental investigation reveals that the novel Pt-Sn/ $\mathrm{Al}_{2} \mathrm{O}_{3}-\mathrm{SAPO}-34$ catalyst and proposed intensified design of fluidized bed reactor is a promising opportunity for direct propane dehydrogenation to propylene, with both economic and operational benefit. The experimental setup is shown in Figure 7 while catalyst and experimental design information can found elsewhere [10, 13-18].
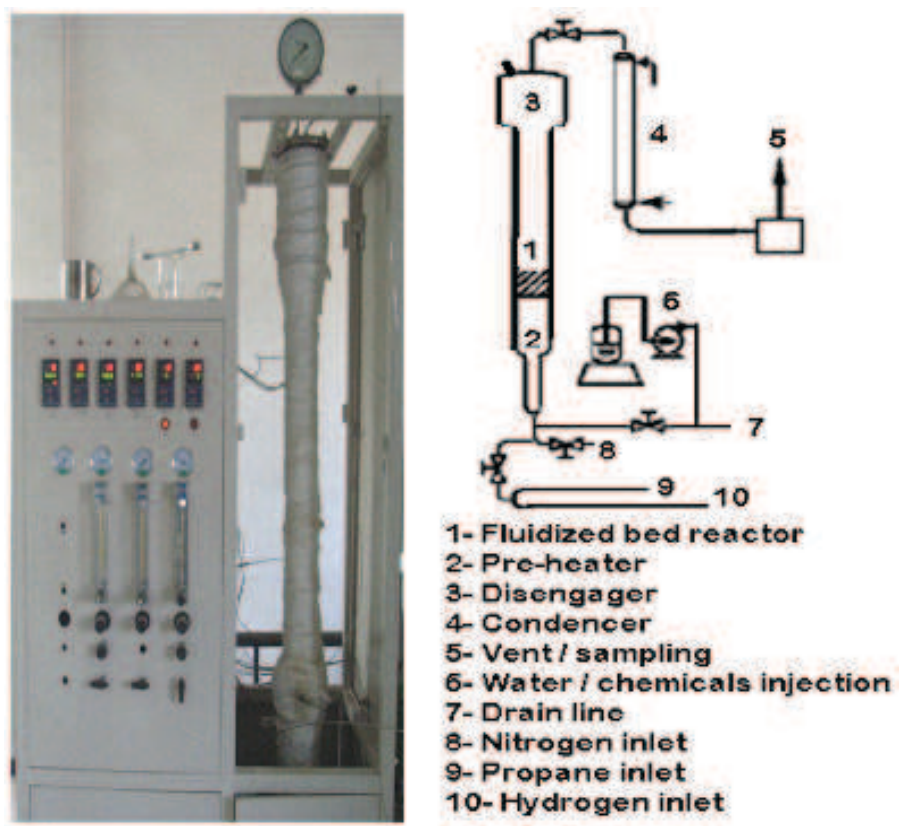

Fig. 7. Hot-model bi-model particle Fluidized Bed Reactor (FBR) apparatus.

The experimental results of propane dehydrogenation using novel catalyst $\mathrm{Pt}-\mathrm{Sn} / \mathrm{Al}_{2} \mathrm{O}_{3}-$ SAPO-34 using bi-modal pilot scale fluidized bed reactor are shown in Figure 8 . The comparison demonstrates that bi-model results are far better than fixed and single particle fluidized bed [10]. The influence of fluidization mode in an integrated bi-model particle fluidized bed was also investigated for propane dehydrogenation to propylene. It is observed that the propylene selectivity in a fluidized bed reactor was improved after $1 \mathrm{hr}$ 
operation, when the reactor reaches steady state conditions. The steady and uniform conversion and yield is also achieved. Actually, in fixed bed reactor coke deposition is high as compared to fluidized bed reactor (see Table 1). In the two particles co-fluidized system it was observed that the coke deposited on SAPO-34 (fine catalyst particles) is higher than the metal incorporated SAPO-34 (principal catalyst). Therefore, it's easy for principal dehydrogenation catalyst (Pt-Sn/ $\mathrm{Al}_{2} \mathrm{O}_{3}-\mathrm{SAPO}-34$ ) to sustain its activity for longer duration.

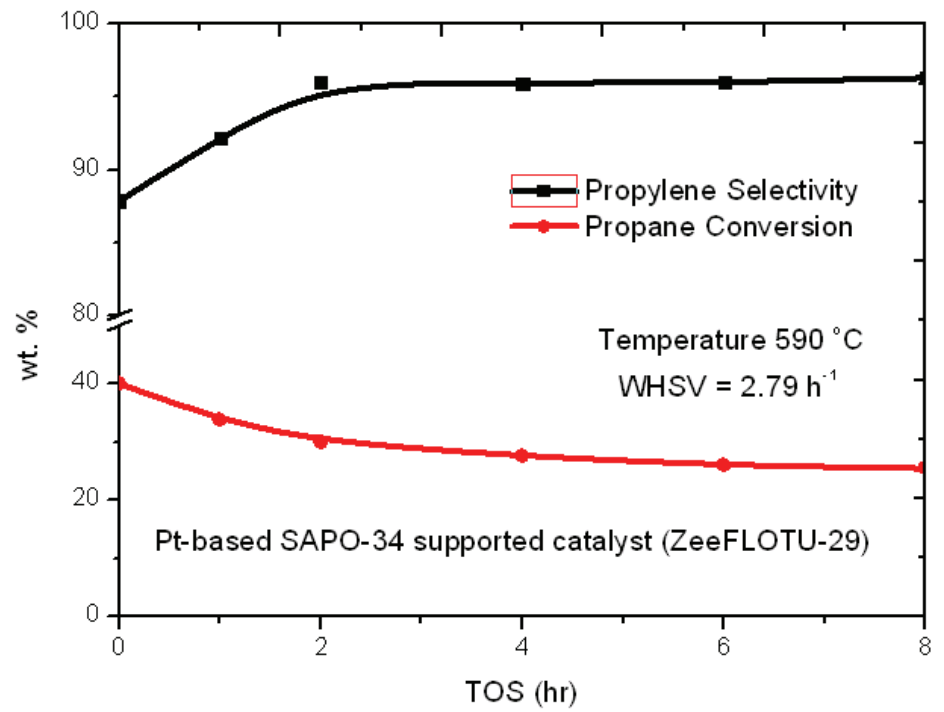

Fig. 8. Performance comparison of novel catalyst in fixed bed with proposed GSS-fluidized bed reactor

\begin{tabular}{ccc}
\hline Reactor & aCoke $(w t . \%)$ & bDeactivation (\%) \\
\hline Fixed bed & 0.41 & 54 \\
Fluidized Bed & 0.24 & 45 \\
\hline
\end{tabular}

${ }^{\mathrm{a}} \mathrm{O}_{2}$-pulse coke analysis

beactivation $=\left[\left(\mathrm{X}_{0}-\mathrm{X}_{\mathrm{f}}\right) / \mathrm{X}_{0} \times 100\right]$;

where, $X_{0}$ is the initial conversion at $5 \mathrm{~min}$. and $X_{\mathrm{f}}$ is the final propane conversion

Table 1. Deactivation rate and amount of coke formed on principal catalyst (Pt-Sn/AlSAPO-34)

Moreover, in the continuous processing the small catalysts (those serve as heat carrier) were continuously regenerated and the process efficiency was improved. Above $96 \%$ propylene selectivity was obtained at $8 \mathrm{hr}$ time-on-stream. Sustainable conversion with lower deactivation rate (see table 1) was also observed. The lower propylene yield initially was due to lower conversion and selectivity, which increase gradually with time. Therefore we can say that the impressive results were obtained using this integrated fluidized bed reactor. It was interesting to find that the reaction stability and activity of catalyst will become superior, but also superior in coke management. Nevertheless, deactivation and/or activity loss of the bi-metallic catalysts is due to coke deposition and Pt sintering [13-15]. Therefore, 
in coke analysis of bi-model particle fluidized bed catalyst it was noted that large amount of coke is deposited over non-metallic SAPO-34, that is in a continuous recirculation through the regenerator, in continuous setup. It's an effective way to protect catalyst activity for longer time with stable activity, and so called coke management.

The overall picture of selective propane dehydrogenation to propylene over above said catalyst at $590{ }^{\circ} \mathrm{C}$ in bi-modal fluidized bed reactor is shown in the OPE plot in Figure 9. The data was plotted with respect to yields and selectivity. The best propane conversion range to have high propylene yield and selectively is observed to be between $24-28 \%$ conversions. In designated operating range the propylene yield is above $25 \%$ and selectivity is as high as 96 $\%$. While at higher conversions both propylene yield and selectivity dropped sharply, with the increase in ethane formation. It is further noted that the higher conversion favours both cracking and hydride transfer reaction with the decrease in dehydrogenation rate. Moreover, the deactivation of catalyst may also lead to cracking.

The performance of the $\mathrm{Pt}-\mathrm{Sn} / \mathrm{Al}_{2} \mathrm{O}_{3}-\mathrm{SAPO}-34$ is evaluated in a continuous mode of reaction-regeneration for three cycles. The results are shown in Table 2 . The catalysts were regenerated with nitrogen mixed steam for $4 \mathrm{hr}$ at $600{ }^{\circ} \mathrm{C}$. After regeneration, the Pt was redispersed using $\mathrm{C}_{2} \mathrm{Cl}_{2} \mathrm{H}_{4}$ solution, injected with nitrogen at $500{ }^{\circ} \mathrm{C}$. The detailed chlorination method can be finding elsewhere [13, 15]. After the regeneration and re-dispersion of $\mathrm{Pt}$, catalyst was reduced in hydrogen environment, and reused for next reaction cycle at identical conditions. The results clearly demonstrate hydrothermal stability of the catalyst. Therefore, the robustness of proposed design of bi-model particle (Gas-Solid-Solid) fluidized bed reactor and Pt-Sn/ $\mathrm{Al}_{2} \mathrm{O}_{3}-\mathrm{SAPO}-34$ is successfully proved.
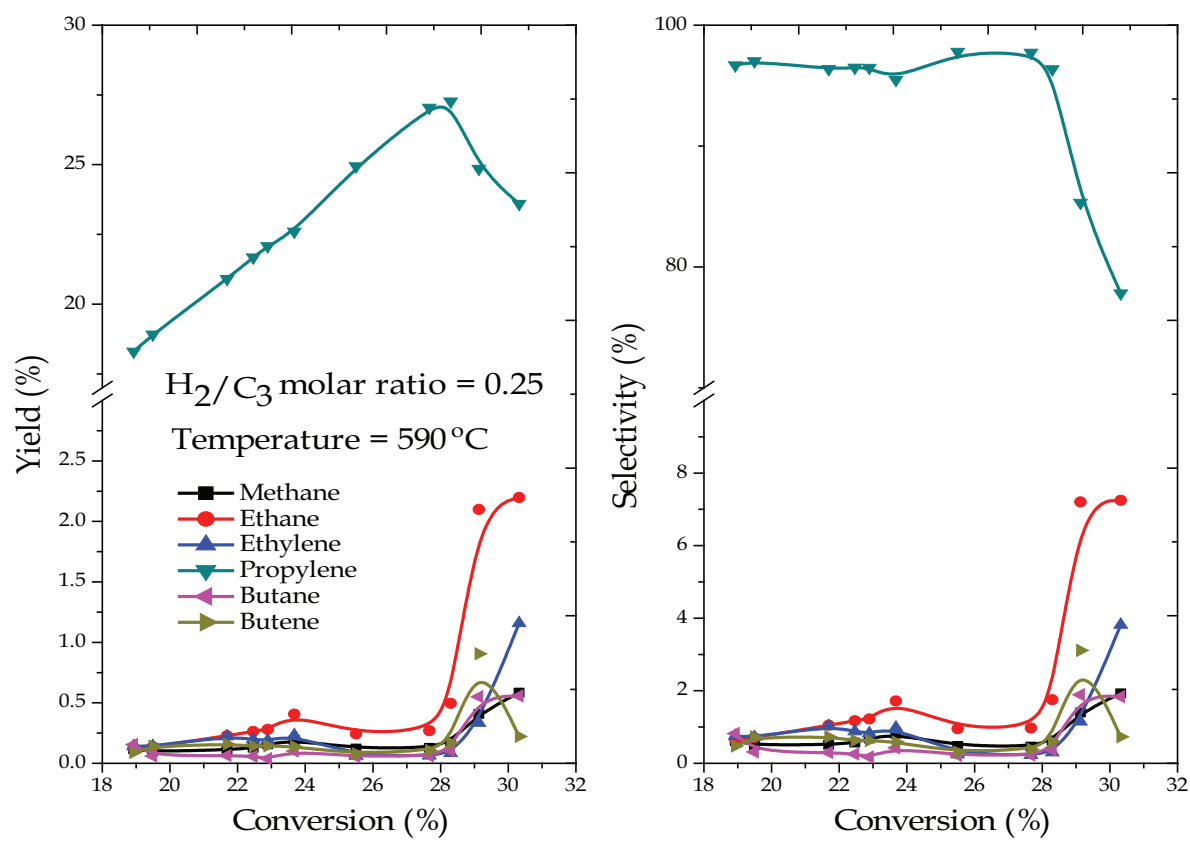

Fig. 9. OPE with respect to yield and selectivity 


\begin{tabular}{cccccccccccccc}
\hline Al-SAPO-34 & \multicolumn{4}{c}{ Cycle I } & \multicolumn{4}{c}{ Cycle II } & \multicolumn{4}{c}{ Cycle III } \\
\cline { 2 - 15 } supported & Conversion & \multicolumn{2}{c}{ Selectivity } & \multicolumn{1}{c}{ Conversion } & Selectivity & Conversion & Selectivity \\
\hline TOS & $1 \mathrm{hr}$ & $8 \mathrm{hr}$ & $1 \mathrm{hr}$ & $8 \mathrm{hr}$ & $1 \mathrm{hr}$ & $8 \mathrm{hr}$ & $1 \mathrm{hr}$ & $8 \mathrm{hr}$ & $1 \mathrm{hr}$ & $8 \mathrm{hr}$ & $1 \mathrm{hr}$ & $8 \mathrm{hr}$ \\
\hline Pt-Sn-based & 29.1 & 26.2 & 85.4 & 96.8 & 28.3 & 25.5 & 85.9 & 96.9 & 27.2 & 24.6 & 87.9 & 97.4 \\
\hline
\end{tabular}

Table 2. Influence of hydrothermal treatment and catalysts performance in a continuous operation (Reaction conditions: $\mathrm{T}=590^{\circ} \mathrm{C}$, WHSV $=5.6 \mathrm{~h}-1, \mathrm{H} 2 / \mathrm{C} 3 \mathrm{H} 8$ molar ratio $=0.25$ )

\section{Heat transfer analysis of bi-modal (G-S-S) fluidization system}

In order to evaluate the heat transfer efficiency of the bi-modal fluidized bed reactor, the analysis is derived from an energy balance and a mass balance with the following simplifying assumptions: the powder particles are not considered individually but as a single phase, motion and temperature gradients are considered only in the direction of flow, the course particle bed is considered to be dilute packing as per total volume of the bed, then the heat transfer from the powder (fine particles) to packing (course particles) is considered as question. Under such assumptions, a plug flow model is established to study heat transfer. In the hot model experiments, since the fine particle mass flux could not be measured, the powder-to-gas mass flux ratio, $R_{s g}\left(G_{s} / G_{g}\right)$ is analyzed. The best value for $R_{s g}$ has to be found by trial and error, by experiments. A suitable $R_{\mathrm{sg}}$ should satisfy the condition of higher conversion and selectivity, and is closed to axial distribution of temperature in experiments [19]. The experiments demonstrate that the temperature is almost uniform with $+/-10{ }^{\circ} \mathrm{C}$ in the co-fluidized bed to keep propane conversion in reasonable range. The Gs/Gg values calculated were also calculated for the same superficial gas velocity. It is worthwhile to note that the temperature of the pre-heated propane injection $\left(550{ }^{\circ} \mathrm{C}\right)$ was taken to $590{ }^{\circ} \mathrm{C}$ for a highly endothermic reaction and maintained because of the continuous supply of heat through fine particles. The dimensionless $R_{h}$ is defined as follows:

$$
R_{h}=\sum\left(\Phi_{i} C p_{g, i}\right)+W_{s} C p_{s} / \Phi_{\text {propane }} C p_{g, \text { propane }}
$$

where i stands for propane, propylene and hydrogen. The higher $R_{h}$ is found to be beneficial for supplying reaction heat and its increases with the increase in fine particle mass flux. While the fine particle replaces a portion of feed gases as heat carrier enhances hear transfer rate. The axial distribution of temperature of the GSS-FBR is far superior to that in the adiabatic packed-bed reactor for endothermic reaction.

\section{Summary}

An integrated design of Fluidized Bed Reactors (FBR) having superior heat supply scheme without providing provisions of external or internal source is discussed for endothermic reactions. The state-of-the-art idea of bi-modal particle (Gas-Solid-Solid) fluidization is presented and briefly discussed in all regards. The superior operational benefits, in particular heat transfer were enhancing using bi-modal fluidized bed technology. The technology was discussed with a case study of propane dehydrogenation using GSS-FRB. A generalized heat transfer information for the bi-modal fluidization system with respect to 
case study. The intensified design of GSS-FBR is found to be a promising opportunity for endothermic and exothermic reactions, as heat supply or removal is always a problem.

\section{References}

[1] K. Kato, T. Takarada, N. Matsuo, T. Suto, N. Nakagawa, Int. Chem. Engg. 34, 605 (1994).

[2] T. Nakazato, J. Kawashima, T. Masagaki and K. Kato, Adv. Powder Technol. 17, 433 (2006).

[3] G. Sun, J.R. Grace, Chem. Eng. Sci. 45, 2187 (1990).

[4] H. Xue, W. Zhang, X. Yang, Eng. Chem. Metall. (China), 17, 235 (1996).

[5] F. Wei, Y. Cheng, Y. Jin, Z.Q. Yu, Can. J. Chem. Eng. 76, 19 (1998).

[6] B. Du, Master Thesis of Tsinghua University, Beijing, China, 1999.

[7] B. Du, F. Wei, Chem. Eng. Process. 41, 329 (2002).

[8] Zeeshan Nawaz, Yujian Sun, Yue Chu and Fei Wei, "Mixing behavior and hydrodynamic study of GAS-SOLID-SOLID Fluidization system: Co-Fluidization of FCC and coarse particles", FLUIDIZATION XIII, May 16-21, 2010, Gyeong-ju, Korea.

[9] Zeeshan Nawaz, PhD Thesis of Tsinghua University, Beijing, China, 2010.

[10] Zeeshan Nawaz, Yue Chu, Wei Yang, Xiaoping Tang, Yao Wang and Fei Wei, Study of Propane Dehydrogenation to Propylene in an integrated Fluidized Bed Reactor using Pt-Sn/Al-SAPO-34 novel catalyst, Industrial \& Engineering Chemistry Research, 49 (2010) 4614-4619.

[11] ASTM Standard D-5757-Revised, ASTM, Philadelphia PA, (2006).

[12] Zeeshan Nawaz*, Tang Xiaoping, Xiaobo Wei and Fei Wei, Attrition behavior of small particles in bimodal particles fluidized bed environment: Influence of density and size ratio, Korean J. Chem. Eng., 27(4), 1025-1031 (2010) (DOI: 10.1007/s11814-0100240-5)

[13] Zeeshan Nawaz, Fei Wei and Shahid Naveed, Highly stable Pt-Sn-based, SAPO-34 supported, Al binded catalyst, and Integrated Fluidized Bed Reactor Design for Alkane Dehydrogenation, Pak. Patent Application No. 1127/2009; Chinese Patent Application No. 200910091226.6.

[14] Zeeshan Nawaz, Tang Xiaoping, Qiang Zhang, Wang Dezheng and Fei Wei, A highly selective Pt-Sn/SAPO-34 catalyst for propane dehydrogenation to propylene, Catalysis Communications, 10 (2009) 1925-1930.

[15] Zeeshan Nawaz and Wei Fei, Hydrothermal study of Pt-Sn-based SAPO-34 supported novel catalyst used for selective propane dehydrogenation to propylene, Journal of Industrial and Engineering Chemistry, 16 (2010) 774-784.

[16] Zeeshan Nawaz, Xiaoping Tang, Yao Wang and Fei Wei, Parametric characterization and influence of Tin on the performance of Pt-Sn/SAPO-34 catalyst for selective propane dehydrogenation to propylene, Industrial \& Engineering Chemistry Research, 49 (2010) 1274-1280.

[17] Zeeshan Nawaz and Wei Fei, The Pt-Sn-based SAPO-34 supported novel catalyst for nbutane dehydrogenation, Industrial \& Engineering Chemistry Research, 48 (2009) 7442-7447. 
[18] Zeeshan Nawaz, Tang Xiaoping, Shahid Naveed, Qing Shu and Fei Wei, Experimental Investigation of Attrition Resistance of Zeolite Catalysts in Two Particle Gas-SolidSolid Fluidization System, Pakistan Journal of Scientific \& Industrial Research, 53 (2010) 169-174.

[19] Shuiyuan Huang, Zhanwen Wang, Yong Jin, Studies on gas-solid-solid circulating Fuidized-bed reactors, Chemical Engineering Science 54 (1999) 2067-2075. 


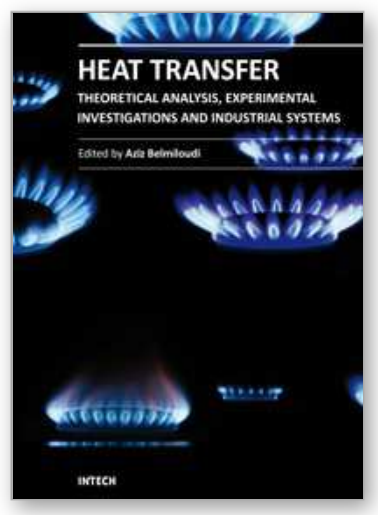

\author{
Heat Transfer - Theoretical Analysis, Experimental Investigations \\ and Industrial Systems \\ Edited by Prof. Aziz Belmiloudi
}

ISBN 978-953-307-226-5

Hard cover, 654 pages

Publisher InTech

Published online 28, January, 2011

Published in print edition January, 2011

Over the past few decades there has been a prolific increase in research and development in area of heat transfer, heat exchangers and their associated technologies. This book is a collection of current research in the above mentioned areas and discusses experimental, theoretical and calculation approaches and industrial utilizations with modern ideas and methods to study heat transfer for single and multiphase systems. The topics considered include various basic concepts of heat transfer, the fundamental modes of heat transfer (namely conduction, convection and radiation), thermophysical properties, condensation, boiling, freezing, innovative experiments, measurement analysis, theoretical models and simulations, with many real-world problems and important modern applications. The book is divided in four sections : "Heat Transfer in Micro Systems", "Boiling, Freezing and Condensation Heat Transfer", "Heat Transfer and its Assessment", "Heat Transfer Calculations", and each section discusses a wide variety of techniques, methods and applications in accordance with the subjects. The combination of theoretical and experimental investigations with many important practical applications of current interest will make this book of interest to researchers, scientists, engineers and graduate students, who make use of experimental and theoretical investigations, assessment and enhancement techniques in this multidisciplinary field as well as to researchers in mathematical modelling, computer simulations and information sciences, who make use of experimental and theoretical investigations as a means of critical assessment of models and results derived from advanced numerical simulations and improvement of the developed models and numerical methods.

\title{
How to reference
}

In order to correctly reference this scholarly work, feel free to copy and paste the following:

Zeeshan Nawaz, Shahid Naveed, Naveed Ramzan and Fei Wei (2011). Integrated Approach for Heat Transfer in Fluidized Bed Reactors, Heat Transfer - Theoretical Analysis, Experimental Investigations and Industrial Systems, Prof. Aziz Belmiloudi (Ed.), ISBN: 978-953-307-226-5, InTech, Available from:

http://www.intechopen.com/books/heat-transfer-theoretical-analysis-experimental-investigations-and-industrialsystems/integrated-approach-for-heat-transfer-in-fluidized-bed-reactors

\section{INTECH}

open science | open minds

\author{
InTech Europe \\ University Campus STeP Ri \\ Slavka Krautzeka 83/A
}

\section{InTech China}

Unit 405, Office Block, Hotel Equatorial Shanghai

No.65, Yan An Road (West), Shanghai, 200040, China 
51000 Rijeka, Croatia

Phone: +385 (51) 770447

Fax: +385 (51) 686166

www.intechopen.com
中国上海市延安西路65号上海国际贵都大饭店办公楼 405 单元 Phone: +86-21-62489820

Fax: +86-21-62489821 
(C) 2011 The Author(s). Licensee IntechOpen. This chapter is distributed under the terms of the Creative Commons Attribution-NonCommercialShareAlike-3.0 License, which permits use, distribution and reproduction for non-commercial purposes, provided the original is properly cited and derivative works building on this content are distributed under the same license. 